\title{
New York University Index to Early American Periodical Literature, I728-1870
} OR THE benefit of those who have used
or may wish to use sometime the annotated periodical index now known as the New York University index to early American periodical literature, it might be of interest to know (I) how it started, (2) what it covers, (3) what kind of national service it can render and has accomplished during its five-year existence, and (4) what work needs to be done to complete it.

\section{How It Started}

The need for a comprehensive index to early American periodical literature covering the first hundred and fifty years had been a long-cherished dream of scholars. Poole's Index did not cover many of the important periodicals published between I 728 and 1870, and its lack of author entries also was a serious drawback to its full use. Therefore, when some years ago federal funds were available for a project to be undertaken by New York University, this index to early American periodical literature was suggested by Professor Cargill, of the New York University English Department. The selection of the 339 periodicals for indexing was made by him and other members of the English department and graduate school faculties. Only very few of these periodicals were indexed in Poole. Fifty-two of the periodicals were published before i 800 .

The work started in January 1934, with a large staff of W.P.A. workers under the direction of Professor Cargill. After five years, about $\mathbf{1} 820$ volumes, representing 339 periodical titles, were indexed, yielding over a million hand-written index cards; but before the work was completed, it was transferred in 1939 to the New York University Library at Washington Square, under the director of libraries, with the understanding that the library would direct and complete the work, within a year put the files of over a million cards in some usable form, and house the project. Today the periodical literature index is fairly complete and it occupies one large room in the library. Before assuming charge of the project, the writer made a survey of the work involved. To her also fell the task of editing, assigning subject headings to over three hundred thousand cards, preparing some selected bibliographies for printing, and acting also as its reference librarian.

\section{What It Covers}

This annotated card index of 339 periodicals published between $\mathrm{I} 728$ to $\mathrm{I} 870$, covers a virgin ground of early Americana preceding all known periodical indexes and for the first time makes easily available to scholars and research students a vast store of basic source material for the study and understanding of early American history, literature, contemporary literary criticism, and political thought of the late eighteenth 
and nineteenth centuries. It is indeed a gold mine for those seeking the earliest appearance in print of many literary works and criticisms, national and local history, the earliest accounts of the West and Northwest, Indians, slavery, Negroes, theatre, drama, music, literature, individual biography, etc. It further reveals the location of thousands of valuable printed items heretofore largely hidden to scholars.

Its most valuable and time-saving feature is the digest of the article which is given on each author and subject card.

The index is divided into five separate alphabetical files, with additional entries under each section:

General articles: Author and subject entries. 600,000 cards with annotations.

Book reviews: Author, and title of book reviewed. I40,000 cards.

Fiction or short stories: Author and title entries. 17,000 cards with annotations.

Poetry: Author, first line, and title entries. 240,000 cards.

Songs (with music scores): Author, composer, first line, and title entries. 8,0oo cards.

\section{National Service}

The chief purpose of this index is to supply, free of cost to scholars and research students throughout the United States, any reference or bibliographical information within its scope. A brief survey of the service it has rendered during its five-year existence may be of interest.

Some fifty universities, colleges, and libraries, besides individuals not connected with institutions, have availed themselves of this reference service either by mail or in person. A record has been kept of all users of the index, the topics searched, and the number of items supplied. Some of the topics searched have resulted in over four hundred items. We have supplied about three thousand items per year. During the war, when there was a drastic reduction in the number of graduate students, more faculty members than students used the index. Some of our most appreciative users have been authors who ask for information about a topic upon which they are doing research. These requests often appear in the New York Times Book Review, in the HeraldTribune Weekly Book Review, and in the Saturday Review of Literature, and we contact the inquirer by letter.

Most of the inquiries for information or use of the index come by mail. Persons in New York or nearby states are advised to come in person, and outsiders have the cards copied for them if this does not require much labor. There is a charge of fifty cents an hour for typing large numbers of cards.

Every name or subject looked up for a scholar gives us the opportunity also to edit the material and make corrections and additions in entries, usually with the advice of the inquirer who is often an expert on that topic.

\section{Work Requiring Completion}

A great amount of work has been done since the project was taken over by the New York University Library in 1939. It is not necessary to enumerate here the task involved and the work accomplished in revising and editing the cards, supplying author entries, assigning specific subject headings to several hundred thousand cards, duplicating many cards for additional subject headings, and filing over a million cards in their respective files. Though a vast amount of work has been accomplished, there is still more to be done. Of particular value would be the following:

I. Assigning specific subject headings and subheads to about two hundred thousand additional cards at present filed temporarily under very broad subjects behind a guide card.

2. Library of ${ }^{\circ}$ Congress subject headings and subject subdivisions have been used 
throughout the completed work as far as possible, but additional subject subdivisions and other subject headings have been used whenever necessary. There are some fifty thousand cards with specific subject headings and subheads assigned but not typed for lack of typists. These are filed back of guide cards and require typing. The index cards used, unfortunately, were not standard library cards with punched holes and, as the name of the periodical appears at the bottom of the card and the digest often runs over on the back of the card, we cannot use a rod. The cards cannot be consulted without taking them out of the files and, therefore, must have all subject headings typed at the top of each card.

3. The name of the author has been supplied in the case of many poems and book review cards which originally did not give the author's name, but still there are ten thousand anonymous book review cards filed under the title of the book reviewed. These should be searched for the author's name.

4. All book review cards relating to America which are anonymous or are entered under the pseudonym, need to be looked up in Sabin for the real name, and a record needs to be made of all Americana titles not in Sabin. Some of this work has been done.

5. Subject cards to be made for book reviews. This has been requested by the users of the index, since even the union catalogs lack the subject approach. Book reviews under a given subject or personal name are much in demand, and some of the books reviewed are not to be found even in large libraries.

6. There is need for further editing and revising of author's names, etc., especially in the general author file.

7. The periodical holdings of New York Public Library, New York Society Library, and Columbia University Library were used in the preparation of this periodical index, but, because some of the files were incomplete, certain volumes were not indexed. The missing volumes should be located and indexed.

8. No doubt partly as a result of the increased, widespread interest of scholars in this index, in I940 the University Microfilms undertook, at the request of the University of Michigan, to reproduce page by page all known periodicals published before 1800 , as no institution or individual possessed all the originals. This is entitled the American Periodical Series, source materials for the study of American culture. Out of the ninety-one titles of periodicals microfilmed for general distribution, forty-four of these titles published before 1800 are among the periodicals in the New York University index. If all the periodicals microfilmed in the American Culture Series were indexed in the near future and incorporated in the New York University index, this accomplishment would decidedly increase the use of these microfilms.

9. This card index cannot be printed or microfilmed because of its present form, but important bibliographies may be published from time to time based more or less on material found in it, supplemented with additional outside material. Three such bibliographies have been compiled by the writer and published: Poe, Whitman, and Emerson. A far more extensive annotated bibliography of over three hundred pages on Hawthorne from 1828 to 1945 is almost completed and is waiting for some foundation or institution willing to finance the cost of printing.

A mimeographed list of the periodicals indexed in this project was sent to twentyfive large libraries for checking. No library had a complete file of all the titles. The ten libraries reporting the largest holdings of the periodicals indexed in order of their completeness were: Library of Congress, New York Public Library, Harvard University Library, Columbia University Library, Cincinnati Public Library, University of Minnesota Library, Cleveland Public Library, Philadelphia Free Library, Duke University Library, and New York Society Library. The Library of Congress lacks forty-three of the 339 periodical titles indexed; New York Public Library, fortyfive; and four of the periodicals did not appear in the Union List of Serials.

All inquiries about the index should be addressed to the director of libraries, New York University, Washington Square East, New York City. 